Vol. 4, Special Issue 1, January 2017

\title{
Optimization of CNC Milling Process by using Different Coatings - A Review
}

\author{
A.B. Shelar ${ }^{1}$, A.M. Shaikh ${ }^{2}$ \\ P.G. Student, Mechanical-Production, K.B.P, Satara, India ${ }^{1}$ \\ Asst Prof, Mechanical-Production, K.B.P, Satara, India ${ }^{2}$
}

\begin{abstract}
Quality and productivity play important role in today's manufacturing market. In machining operations, achieving desired surface quality features of the machined product, is really a challenging job on CNC machine. Now a day's due to very stiff and cut throat competitive market condition in manufacturing industries. The main objective of industries reveal with producing better quality product at minimum cost and increase productivity. CNC milling is most vital and common operation use for produce machine part with desire surface quality and higher productivity with less time and cost constrain. To obtain main project an attempt is made to understand the effect of machining parameters such as cutting speed $(\mathrm{m} / \mathrm{min})$, feed rate $(\mathrm{mm} / \mathrm{min})$, depth of cut $(\mathrm{mm})$ that are influences on responsive output parameters such as Surface Roughness, material removal rate, diamentinal accuracy in this the flatness can be measured by using optimization philosophy. In this work three levels and three parameters are considered; and L27 orthogonal array should be carried out by using two different insert coatings. For the experimentation the wet conditions is taken. In this optimization of milling process parameters using Taguchi method in machining of AISI 316 stainless steel is carried out.
\end{abstract}

Keywords: CNC milling, Taguchi method, Surface roughness, MRR, AISI stainless steel 316.

\section{INTRODUCTION}

Machining is process of producing work piece by removing unwanted material from in the form of chips. This process is very important since almost all the products get their final shape and size by metal removal. Machining offers important benefits such as excellent dimensional tolerances, external and internal geometrical features, surface finish, Removal of heat treat distortion. The machining efficiency is improved by reducing the machining time with high speed machining.

Milling is the process of removing extra work piece material with a rotating multi-point cutting tool, called milling cutter. The machine tool employed for milling is called milling machine.

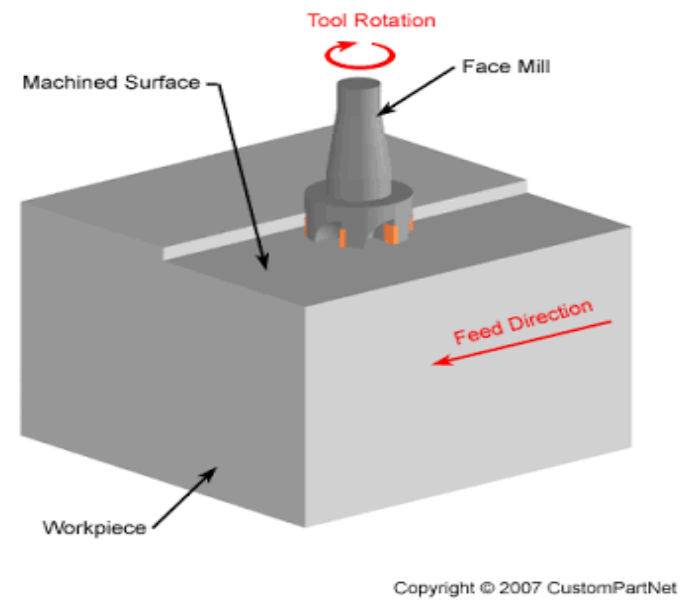

Fig.1Milling operation
Milling machines are basically classified as vertical milling machine or horizontal milling machine. These machines are also classified as knee-type, ram-type, planer-type and bed type. Most milling machines have self-contained electric drive motors, coolant systems, variable spindle speeds, and power-operated and table feeds. The three primary factors in any basic milling operation are speed, feed and depth of cut. Other factors such as kind of material and type of tool materials have a large influence, of course, but these three are the ones the operator can change by adjusting the controls, right at the machine vary from one make of controller to the next. The metal cutting inserts have found wide spread use in today's manufacturing industry especially for hard

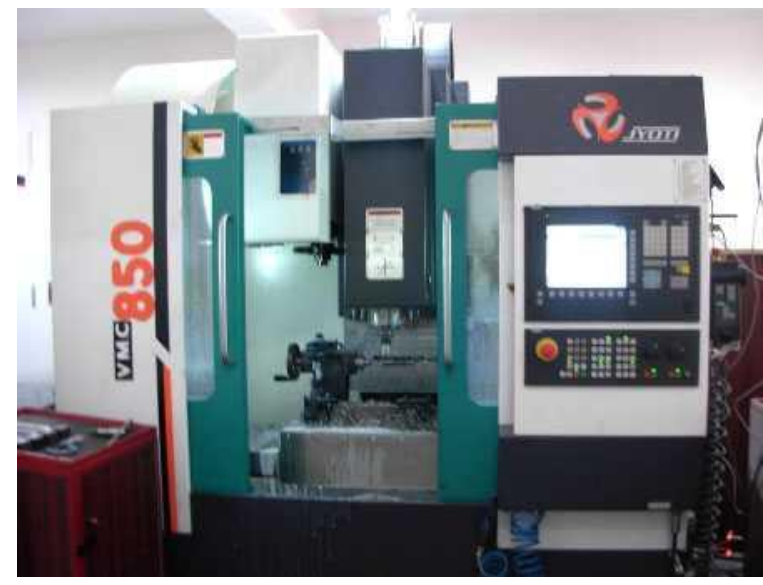

Fig.2 CNC Machining Center (VMC 850) 
IARJSET

International Advanced Research Journal in Science, Engineering and Technology

National Conference on Design, Manufacturing, Energy \& Thermal Engineering (NCDMETE-2017)

AGTI's Dr. Daulatrao Aher College Engineering, Vidyanagar Extension, Karad

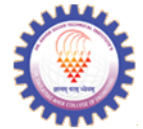

Vol. 4, Special Issue 1, January 2017

materials, which have bought significant improvement in is held parallel. Making sure that any point along the tool performance and cutting parameters through lower surface does not go above or below the tolerance zone. tool wear, reducing cutting forces and better surface finish Modern CMM's are best for measuring the part as they of the work piece. Coated and uncoated inserts are widely can create virtual planes that the true surface profile can be used in the metal-working industry.

\section{CHARACTERISTICS OF CNC MACHINE}

- Flexibility in automation

- Change-over (product) time, effort and cost are much less.

- Less or no jigs and fixtures are needed

- Complex geometry can be easily machined

- High product quality and its consistency

- Optimum working condition is possible

- Lesser breakdown and maintenance requirement.

- Faster deliver a product.

\section{- Surface roughness}

Surface roughness tests are to be conducted on all the samples, after each of the trial with the help of surface roughness tester instrument.The surface roughness is one of the measurable characteristic of surface. The are many different roughness parameters like $\mathrm{Ra}, \mathrm{Rq}, \mathrm{Rz}, \mathrm{Rt}$ among which $\mathrm{Ra}$ is most commonly used.

Arithmetical mean roughness (Ra)-

The average roughness is the area between the roughness profile and it's mean line, or the integral of the absolute value of the roughness profile height over the evaluation length.

$$
R a=\frac{1}{L} \int_{x=0}^{x=L} \text { hi dx }
$$

$\mathrm{L}=$ Sampling length

hi $=$ Deviation from nominal surface

\section{- Material Removal Rate (MRR)}

The material removal rate of the workpiece is measured by ratio of the difference between weight of the workpiece before machining and weight of the workpiece after maching to the machining time that is achieved.

Mathematically,

$$
\mathrm{MRR}=\frac{\mathrm{Wb}-\mathrm{Wa}}{\mathrm{t} \times \mathrm{q}} \times 1000
$$

Where,

$\mathrm{Wb}=$ Weight of the workpiece before maching (grams). $\mathrm{Wa}=$ Weight of the workpiece after maching (grams).

$\mathrm{t}=$ Machining time period (minutes).

$\mathrm{q}=$ Density of work piece material $\left(\mathrm{grams} / \mathrm{cm}^{3}\right)$.

\section{- Dimensional Accuracy}

In the output parameter dimensional accuracy, flatness of the machined work piece can be measured. Flatness for plate production has proven to be important and demands increase as plates become harder, wider and thinner. Today more or less every plate producer checks the flatness either manually or automatically.

Flatness is can be measured using a height gauge run across the surface of the part if only the reference features compared to. Flatness can be measured by simply placing the part on granite slab and running height gauge over it.

\section{CUTTING PARAMETERS}

- Cutting speed: Cutting speed may be defined as the rate (or speed) that the material moves past the cutting edge of the tool, irrespective of the machining operation used. Speed is calculated from the equation;

$$
V c=\frac{\pi D N}{1000}
$$

Where; $\mathrm{Vc}=$ cutting speed,

$\mathrm{D}=$ diameter of milling cutter,

$\mathrm{N}=$ rotational speed of the cutter.

- Feed: Feed rate is the velocity at which the cutter is fed, that is, advanced against the work piece. It is expressed in $\mathrm{mm} / \mathrm{min}$.

- Depth of cut: Depth of cut is the material removal rate, which is the volume of work piece material (metal, wood, plastic, etc.) that can be removed per time unit.

\section{LITERATURE SURVEY}

In concerned with proposed dissertation work, following of the few research work have been reviewed as follows;

Surasti Rawangwong et.al [01] investigates the effect of the main factors on the surface roughness in semi-solid AA 7075 face milling. A $63 \mathrm{~mm}$ diameters fine type carbide tool with twin cutting edge was used for experimentation. The variable factors were the speed, feed rate and depth of cut. The result revealed that the factors affected the surface roughness were the feed rate ratio and the speed, while the depth of cut unaffected the surface roughness. The result of the test showed that the surface roughness was likely to reduce when using the speed $3,800 \mathrm{rpm}$ and the feed rates was $1,000 \mathrm{~mm} / \mathrm{min}$.

W. Li et.al [02] studied the effect of tool wear on surface integrity and its impact on fatigue performance of Inconel 718 alloy by end milling using PVD coated tools. The surface integrity including surface roughness, microstructure, and micro hardness were characterized at three levels of tool flank wear for study. At each level of tool flank wear, the effects of cutting speed, feed, and radial depth-of-cut on surface integrity were investigated. All the milled surfaces had roughness of less than $0.4 \mu \mathrm{m}$, and the majority surface roughness less than $0.25 \mu \mathrm{m}$. Higher tool wear produced less surface roughness.

M. S. Sukumar et.al [03] used taguchi method to identify the optimal combination of influential factors in the milling process. Milling experiment has been performed on Al 6061 material, according to Taguchi orthogonal array (L16) for various roughness ( $\mathrm{Ra}$ ) was measured and recorded for each experimental run and analyzed using Taguchi $\mathrm{S} / \mathrm{N}$ ratios and the optimum controllable parameter combination is identified. An Artificial neural 
IARJSET

International Advanced Research Journal in Science, Engineering and Technology

National Conference on Design, Manufacturing, Energy \& Thermal Engineering (NCDMETE-2017)

AGTI's Dr. Daulatrao Aher College Engineering, Vidyanagar Extension, Karad

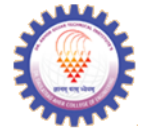

Vol. 4, Special Issue 1, January 2017

network (ANN) model has been developed and trained roughness of aluminium semi-solid 2024 was significantly with full factorial design experimental data and a effect by cutting speed, and feed rate. The surface combination of control parameters have been found from roughness was likely to reduce when the speed was 3,600 ANN for the surface roughness ( $\mathrm{Ra}$ ) value, obtained from $\mathrm{rpm}$ and the feed rates were $1,000 \mathrm{~mm} / \mathrm{min}$. The result also confirmation test, for the optimum control parameters indicated that higher values of speed and lower feed which are obtained from Taguchi $\mathrm{S} / \mathrm{N}$ ratios analysis. tended to decrease the surface.

Taguchi method and ANN found different sets of optimal H. S. Lu et.al [08] investigates optimization design of the combinations but the confirmation test revealed that both got almost same Ra values.

V. Krishnaraj et.al [04] investigates high speed end milling of titanium alloy ( $\mathrm{Ti}-6 \% \mathrm{Al}-4 \% \mathrm{~V}$ ) using carbide insert based end mill cutter. The experiments have been carried out under dry cutting conditions. The cutting speeds selected for the experiments are 120, 150 and180 $\mathrm{m} / \mathrm{min}$. The depth of cuts and feed rate were selected to suit finish machining. For conducting the experiments single insert based cutting tool is used. Experiments were conducted based on the Taguchi's design of experiments, in order to analyse the effect of cutting parameters on cutting force, temperature and surface roughness. From this study it is found that depth of cut and feed rate have higher effect on cutting forces when compared to cutting speed whereas the effect of cutting speed has higher effect on temperature. Results have shown that the milled surface shows the anisotropic nature with the range of surface roughness values from 0.27 to $0.45 \mu \mathrm{m}$ and the range values are highly suitable for finish milling of Ti alloy.

N. Mismiati et.al [05] work focuses on investigating the effect of machined surface inclination angle, axial depth of cut, spindle speed and feed rate for better surface integrity in inclined end milling process utilizing titanium coated carbide ball end mill. Through the analysis, it was found that machined surface inclination angle had great influence on micro hardness and residual stress in the feed direction. As the machined surface inclination angle was increased, the micro hardness also increased. However, residual stress showed the opposite results.

Lohithaksha M. Maiyar et.al [06] investigates the parameter optimization of end milling operation for Inconel 718 super alloy with multi-response criteria based on the taguchi orthogonal array with the grey relational analysis. Cutting speed, feed rate and depth of cut are input parameters and performance characteristics namely surface roughness and material removal rate are selected. It has been also found that the optimal cutting parameters for the machining process lies at $75 \mathrm{~m} / \mathrm{min}$ for cutting velocity, $0.06 \mathrm{~mm} /$ tooth for feed rate and $0.4 \mathrm{~mm}$ for depth of cut. It has been observed that there is a $64.8 \%$ increase in material removal rate and at the same time a $9.52 \%$ decrease in surface roughness. Analysis of variance shows that the cutting velocity is the most significant machining parameter followed by feed rate affecting the multiple performance characteristics with $56.88 \%$ and $34.64 \%$ influence respectively.

cutting parameters for rough cutting processes in highspeed end milling on SKD61 tool steel. The performance measures are tool life and metal removal rate, and the corresponding cutting parameters are milling type, spindle speed, feed per tooth, radial depth of cut, and axial depth of cut. The optimal combination of the cutting parameters obtained from the proposed method is the set with A1, V1, F1, Da2, and Dr3. The corresponding confirmation tests shows that tool life, metal removal rate, and total removal volumes increase by $26.31 \%, 27 \%$, and $60.39 \%$, respectively.

Saurin sheath et.al [09] studied the effect of machining parameters spindle speed, feed and depth of cut were investigated during Face Milling of Wrought Cast Steed grade B (WCB). 23 full factorial designs with four centre points are selected to perform the reliable experiments. Here the response parameters selected are surface roughness and flatness, a form control of Geometric Dimensioning \&Tolerancing (GD\&T). To achieve the desire value of flatness and surface roughness machining parameters need to be controlled. The right selection of process parameters can be achieved through a predictive model. ANOVA has been carried out to know the significance of input parameters. The values predicted from the model and experimental values are very close to each other.

Nik Mismiati et.al [10] performed work on effects of lubricant and milling mode during end milling of S50C medium carbon steel. Numerical factors, namely, spindle speed, feed rate and depth of cut and categorical factors, namely, lubrication and milling mode is optimized using D-optimal experimentation. Results show that minimum residual stress and cutting force can be achieved during up milling, by adopting the $\mathrm{MQL}-\mathrm{SiO}_{2} \mathrm{Nano}$ lubrication system. During down milling minimum residual stress and cutting force can be achieved with flood cutting. Moreover, minimum surface roughness can be attained during flood cutting in both up and down milling. The response surface plots indicate that the effect of spindle speed and feed rate is less significant at low depth of cut but this effect significantly increases the residual stress, cutting force and surface roughness as the depth of cut increases. The obtained values are residual stress of $619.50 \mathrm{MPa}$, cutting force of $36.48 \mathrm{~N}$ and surface roughness of $0.66 \mu \mathrm{m}$.

Thomas Vopat et.al [11] the aim was to determine and compare the wear of ball nose end mill for different types

Surasit Rawangwong et.al [07] investigates the effect of the main factors of the surface roughness in aluminium semi-solid 2024 face milling. The controlled factors were the speed, feed rate and depth of cut. The surface of copy milling operations for various tool materials. Surface roughness in up-copying and down-copying was also measured and compared. In the experiment, the cutting tool material was changed and on the other hand 


\section{IARJSET}

cutting speed, feed rate, axial depth of cut and radial depth $\quad \mathbf{V} \quad \mathrm{S} \quad$ Thangarasu et.al (2012) [16]proposed of cut were not changed. The cemented carbide and high experimentation on AISI 304 Stainless steel material is speed steel were tested as tool materials. The cutting tool taken for the study to determine the parameters and to wear was measured on Zoller Genius 3s universal optimize with Design Of Experiments (DOE) based measuring machine. For carbide mills, the tool life of S2 is Response Surface Method (RSM) to find the optimal $40 \%$ longer than S1 and in case of HSS-Co5 mills; the tool parameter set as per the requirements of the user of the life of S4 is 50\% longer than S3. The results showed that high speed CNC machine. Machining parameters used for tool life of mills in down-copying is longer than mills in optimization are cutting speed, feed rate and depth of cut. up-copying due to lower effective cutting speed during the Hardik G. Soni et.al (2015) [17]studied the optimal copy-milling.

machining parameters on surface roughness and tool wear A. Shokrani et.al [12] presents one of the very first studies on cryogenic CNC end milling of the Inconel 718 nickel based alloy using TiAlN coated solid carbide tools. Cutting parameters selected were tool diameter, cutting speed, fees rate, depth of cut and immersion rate whereas response factors selected were surface roughness, tool wear and power consumption. Statistical analysis of the results revealed that cryogenic cooling has resulted in 33\% and 40\%reduction in Ra and ISO Rz surface roughness of the machined parts as compared to dry machining without noticeable (1.9\%) increase in power consumption of the machine tool. Cryogenic cooling significantly reduced the tool life of the coated solid carbide end mills.

A.K.M. Nurul Amin et.al [13] focuses on a novel approach of minimizing surface roughness in end milling of Mild (Low Carbon) Steel using uncoated WC-Co inserts under magnetic field from permanent magnets. The cutting parameters such as cutting speed, feed and depth of cut and response factor was surface roughness were selected. The feed had the most significant effect on Ra, followed by speed and depth of cut. The optimum cutting speed, feed, and depth of cut were $70 \mathrm{~m} / \mathrm{min}$, $0.10 \mathrm{~mm} /$ tooth, and $1.02 \mathrm{~mm}$, respectively. The significant improvement in surface finish $(\mathrm{Ra}<0.4 \mu \mathrm{m})$ eliminates the need for grinding and polishing

Ahmad Hamdan et.al [14] presents an optimization method of the machining parameters in high speed machining of stainless steel using coated carbide tool to achieve minimum cutting forces and better surface roughness. The standard orthogonal array of L9 was employed in this research work and the results were analysed for the optimization process using $\mathrm{S} / \mathrm{N}$ ratio response analysis and ANOVA to identify the most significant parameters affecting the cutting forces and surface roughness. The input parameters include parameters include the lubrication modes, feed rate, cutting speed, and depth of cut. The result showed a reduction of $25.5 \%$ in the cutting forces and $41.3 \%$ improvement on the surface roughness performance.

Lakshmipathi Tammineni et.al [15] investigated the effect of cutting speed, feed and depth of cut on the surface roughness and flatness of Aluminum 1050 during milling operation. Took trained flatness values and surface roughness are analyzed through graphs generated by using Response Surface Methodology (RSM) of Minitab Software. The surface roughness has been tested using TR-200 surface roughness tester, and the flatness has been tested by using Coordinate Measuring Machine (CMM).

in CNC end milling using AISI 316 as a work piece material and tool used is solid carbide. The machining is done on dry condition .Machining parameters used for optimization are cutting speed, feed rate, depth of cut. In this paper it is studied that there is very few investigator research worked on SS316 stainless steel material.

Alpesh R. Patel A et.al (2013) [18] to studied the effect of machining parameters such as cutting speed, feed rate, depth of cut, no of cutting flute that are influences on responsive output parameters such as Surface Roughness and Material Removal Rate by using optimization philosophy in CNC end milling. This is review paper in this it is find out that there is very few investigator research worked on SS316 stainless steel material so, they want to do work on this material. In this research work we want to investigate influences of input machining parameters like cutting speed, feed rate, depth of cut and no of flute on response parameters like surface roughness and MRR.

V. S. Thangarasu et.al [19] investigates the AISI 304 stainless steel by using Taguchi based Box-Behnken Response Surface Methodology (RSM) method is used to develop prediction formula and Multi Objective Genetic Algorithm (MOGA) is used for High speed CNC milling process optimization with higher Spindle speed, Feed rate and Depth of cut for better surface finish and material removal rate.

Muhammmad Yasiret et.al (2016) [20]investigates the effect of cutting parameters on the surface topography of stainless steel AISI 316L with tungsten carbide tool by using response surface methodology. The experiment is conducted in dry condition. The cutting speeds ranges from $80 \mathrm{~m} / \mathrm{min}$ to $120 \mathrm{~m} / \mathrm{min}$ while feed rates ranges from $0.10 \mathrm{~mm} / \mathrm{rev}$ to $0.14 \mathrm{~mm} / \mathrm{rev}$ were used. Scanning electron microscope (SEM) and Mitutoyo surface tester were used to study in detail the surface topography of stainless steel AISI 316L. According to the results of analysis of variance (ANOVA), feed rate (f) is the most significant parameter on the surface roughness while cutting speed $(\mathrm{Vc})$ is less significant parameter. Constant cutting speed has no effect on the surface roughness but when feed rate was varied the roughness get altered.

Harish Holkar et.al [21] studied the end milling parameters of AISI 321 grade of stainless steel are optimized by using Taguchi method. The end milling tests were carried out with PVD multilayer coated cemented carbide end mill tools. The multilayer coating consists of TiN/TiAlN/TiN coating and the experiments were 
IARJSET

conducted at three different cutting speeds, with three different feed rates, and a constant depth of cut. The results at optimum cutting condition are predicted using estimated signal to noise ratio equation. Analysis and optimization of the dry end milling process has been performed in this research work with help of Taguchi method and ANOVA. The optimization has been done to reduce surface roughness and flank wear with maximization of MRR.

\section{SELECTION OF WORKPIECE MATERIAL}

All Stainless steel materials are tough to work with usually more tough than hard. The Stainless steel is most common and familiar type, they are most easily recognized as nonmagnetic. Stainless steel 316 have some properties such as higher strength, better creep resistance, excellent mechanical properties, excellent corrosion properties, superior oxidation resistance, good fabric ability etc.

\section{TABLE I Chemical composition}

\begin{tabular}{|l|l|}
\hline Element & Composition \\
\hline Carbon $(\mathrm{C})$ & $0.08 \mathrm{max}$ \\
\hline Manganese $(\mathrm{Mn})$ & $2.00 \mathrm{max}$ \\
\hline Silicon $(\mathrm{Si})$ & $0.75 \mathrm{max}$ \\
\hline Sulphur $(\mathrm{S})$ & $0.030 \mathrm{max}$ \\
\hline Phosphorus $(\mathrm{P})$ & $0-0.045$ \\
\hline Chromium $(\mathrm{Cr})$ & $16.0-18.0$ \\
\hline Molybdenum $(\mathrm{Mo})$ & $2.00-3.00$ \\
\hline Nickel $(\mathrm{Ni})$ & $10.0-14.0$ \\
\hline
\end{tabular}

\section{APPLICATIONS OF STAINLESS STEEL 316}

1. Jet engine parts

2. Food productions and storage equipment's

3. Laboratory benches and equipment's

4. Oil and petroleum refining equipment's

5. Medical applications

6. Heat exchangers

\section{REFERENCES}

[01] Surasit Rawangwong, Jaknarin Chatthong, Worapong Boonchouytan, Romadorn Burapa, "Influence of Cutting Parameters in Face Milling Semi-Solid AA 7075 Using Carbide Tool Affected the Surface Roughness and Tool Wear", 11th EcoEnergy and Materials Science and Engineering, Energy procedia 56 ( 2014 ) $448-457$.

[02] W. Li, Y.B. Guo, M.E. Barkey, J.B. Jordon, "Effect Tool Wear during End Milling on the Surface Integrity and Fatigue Life of Inconel 718", 6th CIRP International Conference on High Performance Cutting, 2014, Procedia CIRP 14 (2014) 546 - 551.

[03] M. S. Sukumar, P. Venkata Ramaiah, A. Nagarjuna, "Optimization and Prediction of Parameters in Face Milling of Al-6061 Using Taguchi and ANN Approach", 12th Global Congress On Manufacturing And Management,2014, Procedia Engineering 97 ( 2014 ) $365-371$

[04] V Krishnaraj, S Samsudeensadham, R Sindhumathi, P Kuppan, ,"A study on high speed end milling of titanium alloy", 12th Global Congress On Manufacturing And Management, GCMM 2014, Procedia Engineering 97 ( 2014 ) 251 - 257.

[05] N. Masmiati, Ahmed A.D. Sarhan, "Optimizing cutting parameters in inclined end milling for minimum surface residual stress Taguchi approach", Measurement 60 (2015) 267-275, ISSN 0263-2241.
6] Lohithaksha M Maiyar, Dr.R.Ramanujam , K.Venkatesan , Dr.J.Jerald, "Optimization of Machining Parameters for End Milling of Inconel 718 Super Alloy Using Taguchi Based Grey Relational Analysis", International Conference on DESIGN AND MANUFACTURING, IConDM 2013, Procedia Engineering 64 ( 2013 ) $1276-1282$.

[07] Surasit Rawangwong, Jaknarin Chatthong, Worapong Boon chouytan, and Romadorn Burapa, "An Investigation of Optimum Cutting Conditions in Face Milling Aluminum Semi Solid 2024 Using Carbide Tool", 10th Eco-Energy and Materials Science and Engineering (EMSES2012), Energy Procedia 34 (2013) 854 - 862.

[08] H.S. Lu, C.K. Chang, N.C. Hwang, C.T. Chung, , "Grey relational analysis coupled with principal component analysis for optimization design of the cutting parameters in high-speed end milling", journal of materials processing technology 209 ( 2009 ) 3808-3817.

[09] Saurin Sheth , P. M. George, "Experimental Investigation and Prediction of Flatness and Surface Roughness during Face Milling Operation of WCB Material", 3rd International Conference on Innovations in Automation and Mechatronics Engineering, 23 ( 2016 ) 344-351

[10] Nik Masmiati, Ahmed A.D. Sarhan, Mohsen Abdel Naeim Hassan, Mohd Hamdi, "Optimization of cutting conditions for minimum residual stress, cutting force and surface roughness in end milling of S50C medium carbon steel", Measurement 86 (2016) 253-265.

[11] Tomas Vopat, Jozef Peterka, Vladimir Simna, Marcel Kuruc, "The Influence of Different Types of Copy Milling on the Surface Roughness and Tool Life of End Mills", 25th DAAAM International Symposium on Intelligent Manufacturing and Automation, DAAAM 2014, Procedia Engineering 100 (2015) 868 - 876.

[12] Shokrani, V. Dhokia, S.T Newman, R. Imani-Asrai, "An Initial Study of the Effect of Using Liquid Nitrogen Coolant on the Surface Roughness of Inconel 718 Nickel-Based Alloy in CNC Milling", 45th CIRP Conference on Manufacturing Systems 2012, Procedia CIRP 3 ( 2012 ) $121-125$.

[13] A.K.M. Nurul Amin, Syidatul Akma Sulaima, Siti Noor Izzati Mohd Zainun, M. D. Arif, "Surface Roughness Optimization in End Milling of Stainless Steel AISI304 with Uncoated WC-Co Insert Under Magnetic Field", Advanced Materials Research Vol. 576 (2012) pp 119-122.

[14] Ahmad Hamdan, Ahmed A. D. Sarhan, Mohd Hamdi , "An optimization method of the machining parameters in high-speed machining of stainless steel using coated carbide tool for best surface finish", International Journal of Advance Manufacturing Technology (2012) 58:81-91

[15] Lakshmipathi Tammineni, Hari Prasada Reddy Yedula, "Investigation of influence of milling parameters on surface roughness and flatness", International Journal of Advances in Engineering \& Technology, Jan. 2014. CIJAET ISSN: 22311963

[16] V.S Thangarasu, R. Sivasubramanian, "High Speed CNC Machining Of AISI 304Stainless Steel; Optimization Of Process Parameters" International Journal of Mechanical Engineering and Robotics Research Vol. 1, No. 3, October 2012.

[17] Hardik G. Soni (2015), “A Review on Optimization of end milling forStainless Steel (AISI 316)”, Volume: 5 | Issue: 5 | May 2015 | ISSN - 2249-555X

[18] Alpesh R. Patel , Prof. N. K. Prajapati , “A Review On Optimization Of Machining Parameters For Surface Roughness And Material Removal Rate For SS 316 In CNC End Milling Process", Int. Journal of Engineering Research and Applications, ISSN : 22489622, Vol. 3, Issue 6, Nov-Dec 2013, pp.1965-1969.

[19] V. S. Thangarasu, G. Devaraj, R. Sivasubramanian, "High speed CNC machining of AISI 304 stainless steel; Optimization of process parameters by MOGA", International Journal of Engineering, Science and Technology Vol. 4, No. 3, 2012, pp. 66-77.

[20] Muhammmad Yasir , Turnad Lenggo Ginta, "Effect Of Cutting Speed And Feed Rate On Surface Roughness Of AISI 316L SS Using End-Milling", ARPN Journal of Engineering and Applied Sciences, VOL. 11, NO. 4, February 2016.

[21] Harish Holkar, Mudigonda Sadaiah, "Optimization of End Milling Machining Parameters of AISI 321Stainless Steel using Taguchi Method", International Journal on Recent and Innovation Trends in Computing and Communication ISSN: 2321-8169 Volume: 4 Issue: $420-23$. 